This item was submitted to Loughborough's Research Repository by the author.

Items in Figshare are protected by copyright, with all rights reserved, unless otherwise indicated.

\title{
Low-volume wet-process sprayed concrete: hardened properties
}

PLEASE CITE THE PUBLISHED VERSION

PUBLISHER

Springer Verlag / @ RILEM

VERSION

AM (Accepted Manuscript)

LICENCE

CC BY-NC-ND 4.0

REPOSITORY RECORD

Goodier, Chris I., Simon A. Austin, and Peter J. Robins. 2019. "Low-volume Wet-process Sprayed Concrete: Hardened Properties”. figshare. https://hdl.handle.net/2134/5038. 
This item was submitted to Loughborough's Institutional Repository (https://dspace.lboro.ac.uk/) by the author and is made available under the following Creative Commons Licence conditions.

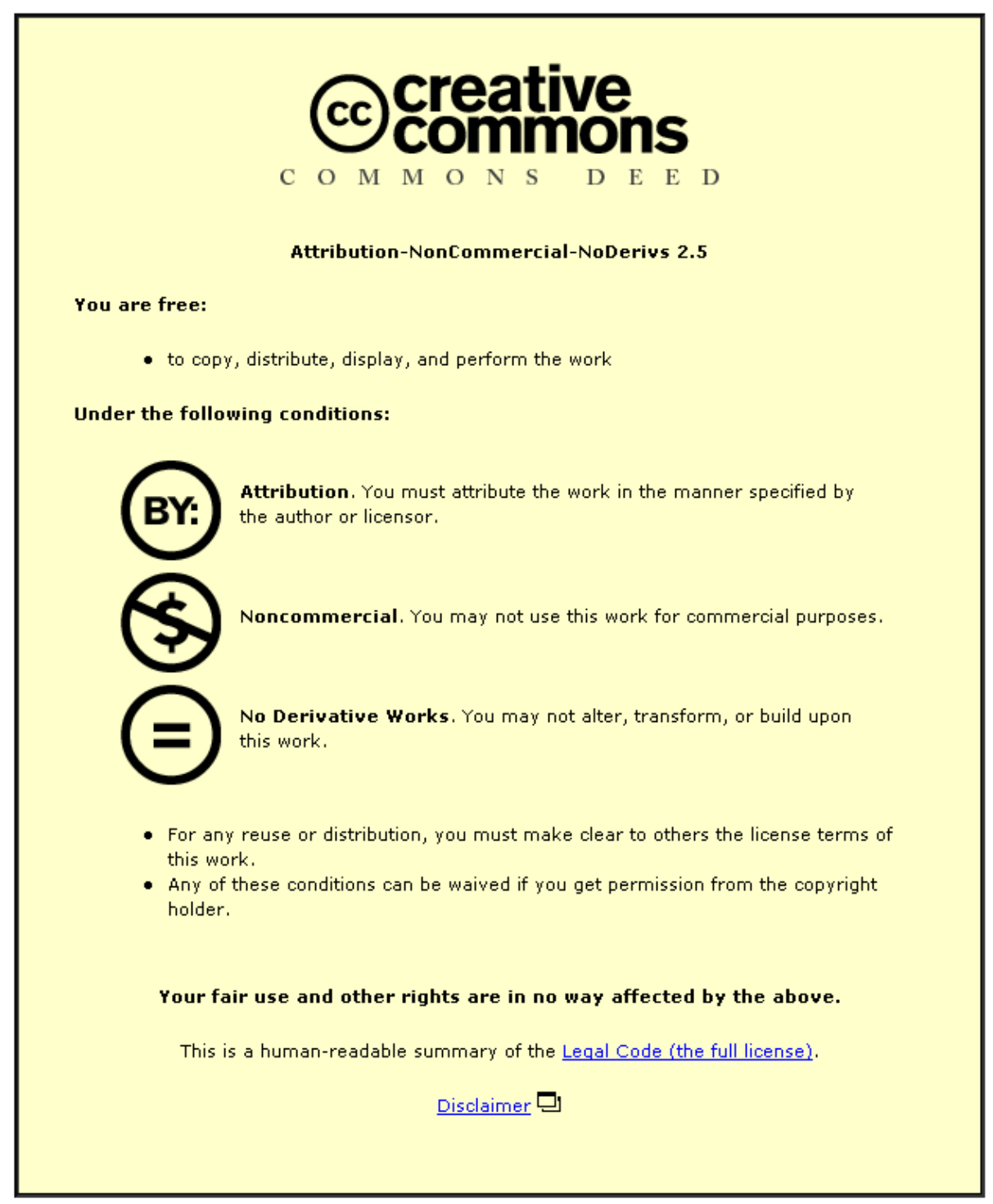

For the full text of this licence, please go to: http://creativecommons.org/licenses/by-nc-nd/2.5/ 


\title{
Low-Volume Wet-Process Sprayed Concrete: Hardened properties
}

\author{
C.I.Goodier ${ }^{1}$, S.A.Austin ${ }^{2}$ and P.J.Robins ${ }^{3}$
}

1. Senior Research Associate, Department of Civil and Building Engineering at Loughborough University, Loughborough, Leics, LE11 3TU.

2. Professor of Structural Engineering, Department of Civil and Building Engineering at Loughborough University, Loughborough, Leics, LE11 3TU.

3. Senior Lecturer, Department of Civil and Building Engineering at Loughborough University, Loughborough, Leics, LE11 3TU. 


\title{
LOW-VOLUME WET-PROCESS SPRAYED CONCRETE: HARDENED PROPERTIES
}

\author{
C.I.Goodier, S.A.Austin and P.J.Robins
}

This paper, which reports on part of a three year research project into wet-process sprayed mortars and concretes for repair, investigates the hardened performance of wet-process sprayed fine concretes. It follows on from an earlier paper by the authors on the performance of hardened wet-process sprayed mortars and some comparisons with these are made here ${ }^{1}$. Work has also been completed by the authors on the pumping and rheology of the fine concrete mixes presented here ${ }^{2}$. Nine laboratory-designed fine concretes were pumped and sprayed through a wetprocess piston pump and one through a dry-process pump. The properties measured included compressive and flexural strength, tensile bond strength, hardened density, elastic modulus, sorptivity and drying and restrained shrinkage. Insitu test specimens were extracted from 500x500x100mm deep sprayed panels. Hardened property tests were also conducted on corresponding cast specimens and, where possible, on specimens that had been sprayed directly into a cube or beam mould.

The compressive strengths of the cast cubes, although very similar, were usually slightly greater than the in-situ cubes, the opposite of what was found for wetsprayed mortars ${ }^{1}$. Inconsistent results for compressive and flexural strengths obtained from spraying directly into a steel mould suggest that this method is not as reliable when using a piston pump as it is when using a low-output worm pump ${ }^{1}$. The bond strength of all the mixes exceeded 2.1 MPa at 7 days. The values for modulus of elasticity, when compared with the compressive strength, were similar to published data for this relationship. The sorptivity values showed only a slight relationship with the compressive strength. The mixes exhibited a wide range of drying shrinkage, but the data from the restrained specimens suggest an actual repair is influenced as much by ambient conditions as it is by the mix proportions. 


\section{Introduction}

Sprayed concrete can be defined as a concrete conveyed through a hose and pneumatically projected at high velocity from a nozzle into place. In the wet process, the constituents (cement, aggregate, admixtures and water) are batched and mixed together before being fed into the delivery equipment or pump. The mix is then conveyed under pressure to the nozzle, where compressed air is injected to project the mix into place. This differs from the dry process in which the dry constituents are batched together before being conveyed under pressure down the delivery hose to the nozzle, where pressurised water is introduced and the mix projected into place. The rheological properties of the mix in the wet process are obviously critical, and the rheological properties of the mixes discussed here were examined by the authors in a previous paper ${ }^{2}$. The rheological performance of wet-sprayed mortars has also been investigated by the authors ${ }^{3,4}$. However, the concrete's hardened properties are of equal importance, so that a durable and long-lasting repair can be obtained, and it is these properties that this paper will investigate.

This paper describes some of the findings from a three-year Government and industry-funded research programme into wet-process sprayed concretes and mortars for repair, which has resulted in an industrial guide published by the Concrete Society ${ }^{5}$. More specifically, this paper describes the hardened properties of a range of fine concrete mixes, which are defined as mixtures of cement, aggregate and water, together with any admixtures and additions. Ten laboratory-designed concretes were tested, consisting of combinations of a $6 \mathrm{~mm}$ maximum uncrushed river gravel, Portland cement, silica fume and water. Additional constituents in some mixes include superplasticiser, air-entrainment, steel and polypropylene fibres, crushed Portland stone and a coarse $(2-8 \mathrm{~mm})$, smooth aggregate. Nine mixes were wet sprayed with a piston pump and one mix was dry sprayed. Previous work on the hardened performance of sprayed concrete is discussed, together with the experimental methods employed to measure the hardened properties of the fine concretes.

The effect of wet spraying varying types of fine concretes (compared with casting) on properties such as compressive, flexural and bond strength, drying shrinkage and elastic modulus is presented. Non-standard tests (together with their results) such as restrained shrinkage are also discussed. Presented together, these results give an overview of the possibilities of the wet process for low-volume concrete repair and 
show that effective repairs with adequate properties can be produced using this process.

\section{Wet-process sprayed fine concrete}

Wet-process sprayed application offers a number of advantages over cast and handapplied repairs, including the reduction or elimination of formwork, the construction of free-form profiles and faster and more efficient construction ${ }^{7}$. It can also provide enhanced hardened properties if properly placed. The performance of a repair material is clearly critical to the success of the remedial works to which they are applied and careful consideration should be given to the choice of repair material and to the properties relevant to the application. Details of previous work conducted into the hardened properties of wet-sprayed mortars was presented in earlier work by the authors $^{1,4,6}$ and only a brief summation is included here. Other previous works published by the authors have discussed the materials, installation and physical properties of sprayed concrete ${ }^{8}$ and the associated application methods and quality considerations $^{9}$.

The interaction between the substrate and the repair material is obviously important and substantial work has been conducted in this area, although little of this is specific to sprayed repair ${ }^{10,11}$. It is generally agreed that properties such as strength, elastic modulus, drying shrinkage and permeability are all critical to the success of a repair.

Hills ${ }^{12}$ conducted tests on wet- and dry-process sprayed concrete, and compared results with those from cast concrete. He concluded that the performance of the sprayed concretes did not appear significantly different from those of properly compacted cast mixes of similar composition and he argued that it was the modified mix design needed for sprayed concretes that altered the hardened properties, not the method of placement. However, it has been argued more recently that cast and sprayed concrete are of a different nature, with the spraying process affecting the internal arrangement of constituents and hence the strength and durability ${ }^{13,14}$.

Gordon conducted work on wet-sprayed pre-blended repair mortars and reported increases in compaction, compressive strengths, and bond strength compared with hand application ${ }^{15}$. Initial results for drying shrinkage also showed similar shrinkage

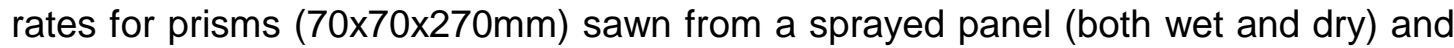
cast prisms of the same size. 
Work has also been conducted on the long term performance ${ }^{16}$ and structural effectiveness $^{17}$ of sprayed-concrete repairs. More published data exists on highvolume wet-sprayed concretes (mainly for tunnelling) and Malmberg showed that the most consistent quality of sprayed concrete is achieved with site-batched wetsprayed concrete when compared with ready mix supplied wet-sprayed concrete and with the dry process ${ }^{18}$. Interest and research into the wet process is constantly increasing, for both high-volume work and repair, including recent applications in the $\mathrm{UK}^{19}$. Garshol ${ }^{20}$ published a study of the international practices and trends in sprayed concrete and concludes that the wet process is now prevalent for medium- to highvolume applications, and is due to dominate further in the future. He also noted the increasing addition of steel fibres in place of mesh reinforcement and the higher priority given to safety and the working environment, which can only increase the potential of the wet process over the dry. Substantial work has also recently been completed by Beaupré et al. ${ }^{21}$ into low-volume wet-process sprayed concrete. He dry- and wet-sprayed several $10 \mathrm{~mm}$ aggregate concretes with different combinations of silica fume, water reducers, superplasticisers, air entrainment and steel and polypropylene fibres. He showed it was possible to wet-spray concretes with a high initial air content (13-19\%) and slump (150-220mm) which would adhere satisfactorily to the receiving surface without sloughing. The entrained air was forced out of the concretes on spraying to leave a residual air content of 5.0-6.8\% and low water/cement ratios (0.3-0.35) and high compressive and flexural strengths were obtained (52-71 MPa at 35 days and 7.5-9.5 MPa at 28 days respectively). Additional work has also been done on using air entrainment for both wet- and dry-process sprayed concretes for repair ${ }^{22}$.

\section{Mix designs}

The constituent proportions of the mixes are shown in Table 1 and the gradings of the aggregates are given in Figure 1, together with the combined grading of one of the mixes (C1p). Only one is shown as the gradings for the mixes were very similar. All the mixes contained a $6 \mathrm{~mm}$ maximum sized uncrushed river gravel and Portland cement conforming to BS12: $1996^{23}$. The fine concretes C4p and C5p also contained a coarse $(2-8 \mathrm{~mm})$ smooth aggregate and $\mathrm{C} 5 \mathrm{p}$ contained a crushed Portland stone. Mix C1Sp contained steel fibres with an aspect ratio of $30 / .50$ (i.e. $30 \mathrm{~mm}$ long and $0.5 \mathrm{~mm}$ diameter) and mixes CP1p and CP2p contained $19 \mathrm{~mm}$ long polypropylene fibres. All the mixes contained silica fume in the form of a water-based slurry with a 
$50 \%$ silica fume content by weight and all the mixes except C 2 , C C $3 p$ and C3Ap contained a superplasticiser. An air entrainment admixture was added to mixes C1Ap and C3Ap. The w/c ratio in Table 1 is the water/total cementitious (i.e. Portland cement and silica fume) value and the Agg/c value is the aggregate/total cementitious value.

\section{Trial Procedure}

The concretes were mixed using an integral forced-action paddle mixer on the rear of a Reed B-10 piston pump, which was also employed to pump the concrete. After mixing, this could be hydraulically loaded into the hopper of the pump. Water was added in the mixer until the desired consistency for spraying was achieved. i.e. workable enough to be pumped yet stiff enough not to slough after being sprayed onto a vertical substrate. All the mixes (except C2d) were pumped with the Reed B10 piston pump and sprayed using a $25 \mathrm{~mm}$ diameter rubber hose, a $365 \mathrm{cfm}$ $\left(0.172 \mathrm{~m}^{3} / \mathrm{s}\right)$ compressor and an output of approximately $80 \mathrm{l} / \mathrm{min}$. A $35 \mathrm{~mm}$ diameter rubber hose was required for mix CP1p owing to the difficulty in pumping the high dosage of fibres through the $25 \mathrm{~mm}$ hose. Mix C2d was pumped with a Reed SOVA dry spray gun using a $25 \mathrm{~mm}$ diameter rubber hose, a $365 \mathrm{cfm}\left(0.172 \mathrm{~m}^{3} / \mathrm{s}\right)$ compressor and an output of approximately $50 \mathrm{l} / \mathrm{min}$.

The concretes were sprayed into $500 \times 500 \times 100 \mathrm{~mm}$ deep panels whilst endeavouring to keep voidage and rebound to a minimum. One panel in each trial contained a $500 \times 250 \times 50 \mathrm{~mm}$ thick grit-blasted concrete substrate which was used to determine the bond strength and a second panel contained a reinforcement cage to assess the degree of bar encasement. Samples were also produced by spraying into $100 \mathrm{~mm}$ cube and $500 \times 100 \times 100 \mathrm{~mm}$ beam moulds to assess the suitability of this production method. Further specimens were cast in two layers on a vibrating table for the determination of compressive and flexural strength, elastic modulus and drying shrinkage. All panels were floated immediately after spraying, sealed with a curing membrane and then moved into a laboratory at room temperature within 2 hours ready for stripping and sawing the following day.

\section{Test Methods}

The test methods followed existing standards where appropriate. In some instances, new test methods were developed specifically for this project and these were 
described in detail by the authors in earlier work on mortars ${ }^{1,6}$. Only a brief description is hence included here.

\section{Sampling}

All material within $50 \mathrm{~mm}$ of the panel edge was discarded to avoid the effects of rebound entrapment. The panels were then sawn across their width into $100 \times 100 \mathrm{~mm}$ sections, which were then cut to length into $400 \mathrm{~mm}$ long beams and $100 \mathrm{~mm}$ square cubes. $229 \times 75 \times 75 \mathrm{~mm}$ prisms were also sawn for elastic modulus and drying shrinkage testing. All samples were sawn approximately 24 hours after spraying and then cured in water at $20 \pm 2^{\circ} \mathrm{C}$. The specimens sprayed and cast into steel moulds were struck and cured in the same manner.

\section{Strengths}

The $55 \mathrm{~mm}$ diameter cores were capped with a sulphur compound, and the $100 \mathrm{~mm}$ in-situ cubes were capped between two steel plates with a 2-3mm layer of highstrength plaster. Compressive cube and core tests were carried out at 28 days in accordance with $\mathrm{BS} 1881^{24}$ and $\mathrm{BS} 1881^{25}$ respectively and the flexural tests were carried out at 28 days in accordance with $B S 1881^{26}$ (under four-point bending). The results quoted for all the strength tests are the average of two specimens, and the compressive strength of the cores have been converted to equivalent cube strengths.

The tensile bond strength was measured using a 'Limpet' pull-off test ${ }^{27}$ at 7 and 28 days. The substrate mix design was based upon earlier work by Austin et al. ${ }^{28}$ and each $250 \times 500 \times 50 \mathrm{~mm}$ substrate was grit-blasted on one side to produce a surface roughness index $(\mathrm{SRI})^{29}$ of approximately $220 \mathrm{~mm}$. The surface was wetted and left until saturated surface dry prior to spraying. Five $55 \mathrm{~mm}$ diameter partial cores were cut through the repair material and into the substrate to a depth of approximately $10 \mathrm{~mm}$ and a $50 \mathrm{~mm}$ diameter steel dolly was then glued to the top of the core and an axial tensile load applied at a rate of $2 \mathrm{kN} / \mathrm{min}$ to failure.

\section{Density}

The saturated hardened densities of the cubes were calculated by weighing in air and determining their volume from measured dimensions.

\section{Modulus of elasticity}


The secant modulus of elasticity was measured at 28 days by a test based upon $\mathrm{BS}_{1881^{30}}$ and more recent work completed at Loughborough by Jones ${ }^{31}$. The specimen strains were recorded over a gauge length of $85 \mathrm{~mm}$ using four LVDTs, the average of which was taken to calculate the modulus. The load was applied at a rate of $0.5 \mathrm{~mm} / \mathrm{min}$ and the load and deformations were digitally recorded using a data acquisition system.

\section{Drying shrinkage}

$75 \times 75 \times 229 m m$ specimens were cast to $B S 1881^{32}$ and sawn from sprayed panels. Pairs of measuring studs were glued to three of the longitudinal faces on a $200 \mathrm{~mm}$ gauge length and the specimens were stored in a climatic cabinet at $20^{\circ} \mathrm{C}$ and $50 \%$ $\mathrm{RH}$. Strain readings were taken at 1,2,3,4,7,14,21 and 28 days and then at 30 day intervals until a constant length was achieved. Each shrinkage value quoted is an average of strains measured across three faces of each of the two prism specimens per mix.

\section{Sorptivity}

For sorptivity testing, $55 \mathrm{~mm}$ diameter cores were taken after 28 days, cut to length and oven dried at $50^{\circ} \mathrm{C}$ for 14 days. The water sorptivity was determined according to the RILEM ${ }^{33}$ method in which the $20 \mathrm{~mm}$ thick dry samples are placed in water to a depth of $2 \mathrm{~mm}$ and the weight gain over time recorded for a period of four hours.

\section{Restrained shrinkage}

This test was developed to represent a typical on-site sprayed repair and is described in detail in the previous paper $^{1}$. Second-hand $593 \times 897 \times 50 \mathrm{~mm}$ paving slabs were grit-blasted and half of the slab was covered with reinforcing mesh at a depth of $30 \mathrm{~mm}$. It was then sprayed to a total thickness of $60 \mathrm{~mm}$, floated, and a curing membrane applied. Three pairs of measuring studs at gauge lengths of $200 \mathrm{~mm}$ were fixed to the face of the repair on each of the reinforced and unreinforced sections and strain readings were taken at similar intervals as for the drying shrinkage specimens. The back of the substrates were also instrumented to monitor the movement of the substrates.

\section{Test results}

Compressive strength 
Figure 2 shows the cube and core strengths of the piston-pumped concretes and the dry-sprayed concrete $\mathrm{C} 2 \mathrm{~d}$, obtained from in-situ cores, cubes sawn from panels and cast and sprayed cubes.

The concrete with the lowest strength of $30.1 \mathrm{MPa}$ was mix CP2p which was sprayed into a cube. However, there are wider differences in compressive strength values for the sprayed cube specimens compared with the other methods of measurement, owing to the difficulties in spraying into a $100 \mathrm{~mm}$ cube with a high-volume, largenozzle piston pump. In contrast, the cast and in-situ cube strengths for each mix were very similar. However, it is generally agreed that in-situ sprayed concretes produce higher strengths than for similarly cast mixes ${ }^{34}$, owing mainly to the greater compaction obtained with the spraying process and this trend was found by the authors for mortars ${ }^{1}$. However, the opposite has also been observed ${ }^{35}$. The core strengths were consistently lower than the other methods of measurement.

Mix C3Ap had the lowest in-situ strength, possibly owing to the lack of superplasticiser compared with the other mixes (which would increase the water/cement ratio) and the presence of air voids (8.5\% after spraying). However, the addition of air to mix C1p (i.e. mix C1Ap) appears to have increased the compressive strength, possibly owing to air in the fresh mix enabling the water content of the mix to be reduced for the same workability. The highest cast and insitu cube strengths were obtained by mixes C4p and C5p, owing mainly to the larger aggregates and lower water/cement ratios employed in the mix designs.

The relationship of the in-situ cube strength with the water/cement ratio is as expected (Figure 3), the trend being similar to data produced by Hills ${ }^{12}$. However, the trend for the sprayed cubes seems opposite to what might be expected. This could be due to the increase in water/cementitious ratio producing a more workable mix that can be sprayed into $100 \mathrm{~mm}$ cube moulds with less voids, hence producing a higher compressive strength.

\section{Flexural strength}

Table 2 shows similarly variable results to the compressive strength results with no apparent trends. The sprayed mould compressive strengths for C1Ap and CP2p are very similar to their in-situ strengths, but the sprayed mould strength for C1Sp is significantly lower. This shows the problems that can occur with voidage and 
rebound when spraying into the beam moulds, especially with a high volume piston pump. More consistent trends were found by the authors when worm-pumping mortars, with the in-situ beams producing higher flexural strengths than the cast beams ${ }^{1}$. The relationship between the flexural and compressive strengths for both cast and in-situ specimens (Figure 4 ) is in line with data for cast concrete ${ }^{36}$.

\section{Tensile bond strength}

The 7 and 28 day vertical bond strengths of the piston-pumped concretes are shown in Figure 5(a) and the vertical bond strengths are compared with the in-situ compressive strengths in Figure 5(b). All the concretes achieved at least $2.1 \mathrm{MPa}$ at 7 days and at least $2.3 \mathrm{MPa}$ at 28 days. The lowest bond strength was obtained with the dry-sprayed $\mathrm{C} 2 \mathrm{~d}$, the opposite of what might be expected.

Figure 5(b) shows that the concretes in this study possess a relatively narrow range of vertical bond strengths (2.3-3.1 MPa), despite having a broad range of in-situ compressive strengths (40.1-80.3 MPa). This compares with a range of 1.7-2.2 $\mathrm{MPa}$ for worm-pumped mortars and 1.4-2.3 MPa for piston-pumped mortars sprayed by the authors ${ }^{1}$.

\section{Density}

The values of density for all the types of cube show no clear trend (Table 3), although the values for density correspond very closely to the values for compressive strength shown in Figure 2. For the mortars wet-sprayed by the authors, the in-situ densities were consistently higher than their cast equivalents ${ }^{1}$. The mix with the highest hardened density was $\mathrm{C} 5 \mathrm{p}$, which was expected due to the higher proportion of coarse aggregate and crushed stone within the mix. The densities obtained from the sprayed moulds were variable compared with the other types of density measurement due to the difficulty of spraying directly into a $100 \mathrm{~mm}$ cube mould.

\section{Modulus of Elasticity}

The elastic modulus is compared with the in-situ compressive strength in Figure 6. There is no agreement on the precise form of this relationship for sprayed concrete $^{33}$, but that from $\mathrm{ACl} 363 \mathrm{R}-92^{37}$ for concrete is shown for comparison. However, a clear trend is difficult to establish owing to the narrow range of compressive cube strengths presented here. The data is important, however, as it is desirable for the elastic modulus of the repair and the substrate to be as similar as 
possible. The results for the wet-sprayed mortars showed lower elastic modulus values compared with in-situ cube strengths than for the fine concretes presented here ${ }^{1}$.

\section{Drying shrinkage}

The drying shrinkage results for the $75 \times 75 \times 229 \mathrm{~mm}$ in-situ prisms are shown in Figure 7. A narrower range of shrinkage values were obtained with the fine concretes compared with the mortars which were wet sprayed by the authors (approximately 900-1500 microstrain at 200 days for the fine concretes compared with 250-2400 microstrain for the mortars ${ }^{1}$ ). This is due mainly to the restraining action of the larger aggregates in the fine concretes and the presence of shrinkage compensators in several of the proprietary mortars. The mix here with the lowest drying shrinkage was $\mathrm{C} 4 \mathrm{p}$. This was due to the high proportion of coarse aggregate and low water/cementitious ratio compared with the other mixes. Mix C5p exhibited a comparatively low amount of drying shrinkage for the same reasons. The drysprayed $\mathrm{C} 2 \mathrm{~d}$ also had a low rate of drying shrinkage owing to its low water/cementitious ratio (as was expected). The highest rates of drying shrinkage were for the two mixes containing polypropylene fibres (CP1p and CP2p). This illustrates that polypropylene fibres should really be added to a mix to minimise plastic shrinkage, and does little to limit drying shrinkage.

The results for mix C1p (Figure 8) show little difference in the shrinkage rates between cast and in-situ prisms when wet-sprayed. Similar rates between cast and in-situ prisms were also observed for wet-sprayed mortars ${ }^{1}$. The dry-sprayed mix C2d exhibited a slightly lower rate of drying shrinkage compared with the wetsprayed mix C1p.

\section{Sorptivity}

The results for sorptivity are shown in Table 4 and their relationship with the in-situ compressive cube strength is shown in Figure 9. The sorptivity test was carried out on the bottom $20 \mathrm{~mm}$ thick section of the core and it is these results that are presented. Recent work by Al-Kindy ${ }^{38}$ has shown that sorptivity decreases with an increase in compressive strength, with the sorptivity of a $50 \mathrm{MPa}$ concrete being 1.52 times lower than similarly cured $30 \mathrm{MPa}$ concrete, the decrease being attributable to the increased cement content and lower w/c ratio. The trend here is only slight and similar results for the mortars wet-sprayed by the authors showed no trend ${ }^{1}$. However, the difference in mix constituents and proportions between the mixes 
presented here each contribute to the spread of results, Al-Kindy's results being based on concretes made with the same constituents.

\section{Restrained shrinkage}

The restrained shrinkage of several mortars, with and without mesh reinforcement, is shown in Figure 10. The results are the average of three gauge readings measured directly from the face of the repair, with no allowance for the movement of the substrate.

The much greater rate of shrinkage of C1Ap and C2d compared with the other mixes could be attributed to the dates on which they were sprayed. C1Ap and C2d were sprayed on the 18 and 19th of June (i.e. the beginning of summer, hence a faster rate of shrinkage owing to a higher ambient temperature) and the other concretes were sprayed in the middle of November (i.e. the beginning of winter, hence a slower rate of shrinkage). The difference in the rates of drying shrinkage due to the time of year at which the mixes were sprayed was also apparent in the wet-sprayed mortars which were sprayed by the authors at the same time as these fine concrete mixes ${ }^{1}$. This influence of the ambient conditions could also explain the expansion of mortars CP2p, C4p and CP1p after 150 days.

The reinforcement mesh had very little influence on the rates of shrinkage, with the mesh-reinforced C3p, C2d and C1Ap mixes actually shrinking slightly more than the corresponding unreinforced mixes. Although the main purpose of reinforcement mesh is to eliminate cracking, no cracking was observed on either the reinforced or unreinforced sections of the slabs. Similar results were found by the authors for the wet-sprayed mortars ${ }^{1}$.

The free drying shrinkage of the $76 \times 76 \times 229 \mathrm{~mm}$ prisms taken in-situ and stored at $20^{\circ} \mathrm{C}$ and $50 \%$ relative humidity are shown for comparison with the restrained specimens for mix C4p in Figure 11(a). The shrinkage of these laboratory stored prisms are considerably greater (more than 4 times in this case) than the free shrinkage deduced from the restrained specimens left outside in ambient conditions. However, the shrinkage rate for the laboratory-stored prisms for mix C1Ap (Figure $11(b)$ ) is considerably closer to the restrained specimens. Evidently, quoting shrinkage results from tests conducted under laboratory conditions should be done with caution when discussing in-situ repairs and their performance. 
Wet sprayed and dry sprayed concrete compared

Table 5 shows the properties of the dry-sprayed mix C2d together with the comparable wet-sprayed mix C1p. The mix designs were similar except for the presence of a superplasticiser in mix C1p. The values for compressive strength for $\mathrm{C} 2 \mathrm{~d}$ are higher than the in-situ C1p but lower than the cast C1p and the flexural strength is slightly higher. The bond strength of the dry-sprayed mix C2d is lower than the wet-sprayed C1p, which is the opposite of what might be expected.

For the dry-sprayed mixes it would be expected that the compressive, flexural and bond strengths might be higher, as well as the values for elastic modulus and density owing to a lower water/cementitious ratio and a higher in-situ cement content compared with the wet-sprayed concrete. However, the presence of the superplasticiser in the wet-sprayed mix decreases the water/cementitious ratio of the wet mix. The hardened density, flexural strength and elastic modulus were all higher, but the compressive cube and bond strengths were lower.

\section{Conclusions}

The results of the hardened property tests on these wet-sprayed fine concretes show that such concretes are suitable repair materials for wet-mix application. Their hardened performance compared with the dry-sprayed fine concrete was similar, although the healthier working environment and the greater control of the mix constituents makes the wet process a superior choice as a repair process. Of particular attraction to the designer/specifier is the knowledge that the mix specified, once pumped and sprayed, will be the mix in-situ (without the uncertainty of the water content controlled by the nozzleman in the dry process, and the further affect of differential rebound). However, the ability to obtain representative quality control specimens by spraying directly into steel moulds is not as consistent as it is when spraying mortars with a low-volume worm pump, although it could still be employed if care is taken in spraying the specimens and interpreting the results.

\section{Compressive and Flexural Strength}

The correlation between the in-situ and the sprayed mould compressive cube strengths is not as consistent as that for wet-sprayed mortars ${ }^{1}$, although comparisons can be made providing that no large voids or excessive rebound is present. However, it is difficult to spray into a $100 \mathrm{~mm}$ cube mould with a piston pump 
without creating voids or entrapping rebound. The highest compressive strengths were obtained with the larger-aggregate mixes C4p and C5p.

\section{Tensile Bond Strength}

The fine concretes all possessed a relatively narrow range of bond strengths (2.3-3.1 $\mathrm{MPa}$ at 28 days) compared with their compressive strengths. The bond strengths were also considerably higher than for similarly sprayed mortars

\section{Modulus of Elasticity}

The results for the modulus of elasticity, when compared with the compressive strength, show a similar trend compared with published formulas of this relationship, although a wider range of compressive strengths would be needed to accurately report a trend.

\section{Drying Shrinkage}

The large-aggregate and dry-sprayed fine concretes shrank less than the other mixes, as was expected. The cast and the in-situ prisms exhibited very similar rates of drying shrinkage, suggesting that cast prisms could be monitored for quality control purposes to measure and monitor in-situ drying shrinkage. The dry-sprayed mix exhibited a slower rate of drying shrinkage than the similar wet-sprayed mix. A narrower range of drying shrinkage was also found compared with the wet-sprayed mortars.

\section{Sorptivity}

The sorptivity showed a slight decrease with increasing in-situ compressive strength, although the spread of results was wide.

\section{Restrained Shrinkage}

The shrinkage strains of the repair suggest that the shrinkage of a sprayed repair is influenced more by the ambient conditions (mainly temperature and humidity, but also rain, wind and sunlight) than by the composition of the mix itself. The inclusion of reinforcement mesh within the repair also seems to have little affect on the measured values of shrinkage taken from the face of the repair. Similar results were also found previously by the authors for wet-sprayed mortars ${ }^{1}$.

\section{Acknowledgements}


The authors are grateful for: the financial support of the EPSRC (Grant number $\mathrm{GR} / \mathrm{K} 52829$ ); the assistance of the industrial collaborators Balvac Whitley Moran, Fibre Technology, Fosroc International, Gunform International Ltd and Putzmeister UK Ltd; and the supply of additional materials by Bekaert, Elkem, Fibermesh, Ronacrete Ltd and Sika Ltd. 


\section{References}

1 AUSTIN, S.A., ROBINS, P.J. AND GOODIER, C.I., The Performance of Hardened Wet-Process Sprayed Mortars, Magazine of Concrete Research, 2000, 52, No.3, June, pp.195-208.

2 AUSTIN, S.A., GOODIER, C.I. AND ROBINS, P.J., Low-Volume Wet-process Sprayed Concrete: Pumping and Spraying, Materials and Structures, RILEM, March 2005, Vol.38, pp.229-237.

3 AUSTIN,S.A., ROBINS, P.J.R. AND GOODIER, C.I. The Rheological Performance of Wet-process Sprayed Mortars. Magazine of Concrete Research, Vol.51, No.5, Oct. 1999.

4 GOODIER, C.I., AUSTIN,S.A. AND ROBINS, P.J.R., An Evaluation of Repair Mortars Installed by Worm-Pump Spraying, Procs. of the Int. Conf. on Engineering Developments in Shotcrete, Hobart, Tasmania, Australia, 2-4 April, 2001, pp. 103110.

5 AUSTIN, S.A., ROBINS, P.J. AND GOODIER, C.I., Construction and Repair with Wet Process Sprayed Concrete and Mortar, Technical Report No.56, The Concrete Society, Crowthorne, 2002.

6 GOODIER, C.I., Wet process sprayed concrete and mortar for repair, PhD thesis, Loughborough University, 2001.

7 AUSTIN, S.A., 'Repair with sprayed concrete', Concrete, Vol. 31, No 1, January 1997, pp. 18-26.

8 AUSTIN, S.A., ROBINS, P.J.R. (eds.). Sprayed Concrete: properties, design and installation, Whittles Publishing, Latheronwheel, UK (ISBN 1-870325-01-X) and McGraw Hill, USA (ISBN 0-07-057148-1), 1995, 382 pp.

9 AUSTIN, S.A., 'Concrete repair with sprayed concrete; methods and quality issues', Procs. of Int. Conf. on Deterioration of Reinforced Concrete in the Gulf and Methods of Repair, Muscat, Oman, December 1996, pp. 165-185.

10 MANGAT, P.S., LIMBACHIYA, M.K., Repair Material Properties which Influence Long-Term Performance of Concrete Structures. Construction and Building Materials, 1994, Vol.9, No.2, pp. 81-90.

11 EMBERSON, M.K. AND MAYS, G.C. Significance of property mismatch in the patch repair of structural concrete, Part 1, Properties of repair system. Magazine of Concrete Research, 1990, 42(152), pp. 147-160.

12 HILLS, D.L., Site-produced sprayed concrete, Concrete, 1982, 16(12). pp. 44-50. 
13 BANTHIA, N., BINDIGANAVILE, V., CHAN, C. Shotcrete: Is it just another Concrete? Procs. Int. Conf. on Infrastructure Regeneration and Rehabilitation, University of Sheffield, UK, June 28th, 1999.

14 BANTHIA, N., Fracture Toughness of Fiber Reinforced Shotcrete: Issues and Challenges, Procs. of the Int. Conf. on Engineering Developments in Shotcrete, Hobart, Tasmania, Australia, 2-4 April, 2001, pp. 3-6.

15 GORDON, K., Wet-spraying of pre-packaged mortars for concrete repair, Proc. of European seminar and workshop on sprayed concrete, Loughborough University, Loughborough, UK, 3 Oct. 1991, pp.9.

16 MANGAT, P.S. AND O'FLAHERTY, F.J., Long Term Performance of Sprayed Concrete Repair in Highway Structures, Sprayed Concrete Technology, E\&FN Spon (ISBN 0-419-22270-7), London, 1996.

17 MAYS, G.C. AND BARNES, R.A, Sprayed Concrete Repairs - Their Structural Effectiveness, Sprayed Concrete Technology, E\&FN Spon (ISBN 0-419-22270-7), London, 1996.

18 MALMBERG, B., Quality and Quality Variations of Wet and Dry Mix Shotcrete Experiences from Grodinge Railway Track Project, Shotcrete for Underground Support VII, Proc. of the Engineering Foundation Conf., Telfs, Austria, June 11-15, 1995, pp.251-258.

19 FOORD, R., Kent Rail Tunnel Refurbishments Sealed Up, Concrete, Nov./Dec. 2005, pp.74-76.

20 GARSHOL, K.F., Shotcrete: International Practices and Trends, Specialist Techniques and Materials for Concrete Construction, Proc. of the Creating with Concrete Conf., Dundee, Scotland, UK, Sept. 8-10, 1999, pp.163-172.

21 BEAUPRE, D., DUMAIS, N., MERCIER, S., LACOMBE, P. AND JOLIN, M., Innovations in the Field of Shotcrete Repairs, Specialist Techniques and Materials for Concrete Construction, Proc. of the Creating with Concrete Conf., Dundee, Scotland, UK, Sept. 8-10, 1999, pp.154-162.

22 BEAUPRE, D., JOLIN, M., PIGEON, M. AND LACOMBE, P., Recent Developments in the Field of Shotcrete: the Quebec Experience, Procs. of the Int. Conf. on Engineering Developments in Shotcrete, Hobart, Tasmania, Australia, 2-4 April, 2001, pp. 47-51.

23 BRITISH STANDARDS INSTITUTION, Specification for Portland cements. BS12: 1996, British Standards Institution, London. 
24 BRITISH STANDARDS INSTITUTION, Testing Concrete: Method for Determination of the Compressive Strength of Concrete Cubes, BS1881: Part116: 1983, British Standards Institution, London.

25 BRITISH STANDARDS INSTITUTION, Testing Concrete: Method for Determination of the Compressive Strength of Concrete Cores, BS1881: Part120: 1983, British Standards Institution, London.

26 BRITISH STANDARDS INSTITUTION, Testing Concrete: Method for Determination of Flexural Strength, BS1881: Part118: 1983, British Standards Institution, London.

$27 \mathrm{MCLEISH}$, A., Standard tests for repair materials and coatings for concrete, CIRIA Technical note 139, CIRIA, London, 1993.

28 AUSTIN,S.A., ROBINS, P.J.R. AND PAN, Y., Tensile Bond Testing of Concrete Repairs, Materials and Structures, 28, 1995, pp.249-259.

29 COMITÉ EUROPÉEN DE NORMALISATION (CEN), TC104/WG10/TG3, Report of 8th Meeting, Zurich, 1999.

30 BRITISH STANDARDS INSTITUTION, Method of Determination of Static Modulus of Elasticity in Compression, BS1881: Part121: 1983, British Standards Institution, London.

31 JONES, P.A., Flexural Modelling of Steel Fibre Reinforced Sprayed Concrete, PhD Thesis, Loughborough University, August 1998, pp.145-155.

2932 BRITISH STANDARDS INSTITUTION, Determination of Changes in Length on Drying and Wetting (Initial Drying Shrinkage, Drying Shrinkage and Wetting Expansion), BS1881: Part5: 1970, British Standards Institution, London.

33 RILEM Technical Committee 14-CPC, Tentative Recommendations No 11.2, Absorption of Water by Capillary, Mater. Struct., Vol.7, No 40, 1974, pp.295-297.

34 CODE OF GOOD PRACTICE, Sprayed Concrete Association.

35 BANTHIA, N., TROTTIER, J.F., BEAUPRE, D., Steel-Fiber-Reinforced Wet-Mix Shotcrete: Comparisons with Cast Concrete, Journal of Materials in Civil Engineering, Vol. 6, No3, August 1994.

36 NEVILLE, A.M., Properties of Concrete, 4rd edition, Longman, London, UK, 1995, p.270.

$37 \mathrm{ACl}$ 363R-92, State-of-the-art report on high-strength concrete, ACl Manual of Concrete Practice Part 1: Materials and General Properties of Concrete, 55pp., Detroit, Michigan, 1994.

38 AL-KINDY, A., Macro and microclimate effects on cover zone properties of field cured concrete, PhD thesis, Loughborough University, December 1998, p.306. 


\section{Low-Volume Wet-Process Sprayed Concrete: Hardened Properties}

Table 1. Mix designs of fine concretes.

\begin{tabular}{|c|c|c|c|c|c|c|c|c|c|c|}
\hline Mix & $\begin{array}{l}\text { San } \\
d\end{array}$ & $\begin{array}{c}\text { Portland } \\
\text { stone } \\
\end{array}$ & Shingle & PC & $\%$ of PC & ratio & $\mathrm{Kg} / \mathrm{m}^{3}$ & $\begin{array}{c}\text { Silica Fume } \\
\text { \% of PC } \\
\end{array}$ & $\begin{array}{l}\text { w/c } \\
\text { ratio }\end{array}$ & $\begin{array}{l}\text { Air } \\
\\
\%\end{array}$ \\
\hline C1p & 2.7 & -- & -- & 1 & 1.5 & 2.6 & -- & 5 & & -- \\
\hline C1Sp & 2.7 & -- & -- & 1 & 1.5 & 2.6 & Steel- 80 & 5 & & -- \\
\hline C1Ap & 2.7 & -- & -- & 1 & 1.5 & 2.6 & -- & 5 & 0.39 & 15.0 \\
\hline C2d & 2.9 & -- & -- & 1 & -- & 2.8 & -- & 5 & & -- \\
\hline C3p & 3.1 & -- & -- & 1 & -- & 3.0 & -- & 5 & 0.63 & -- \\
\hline СЗАр & 3.1 & -- & -- & 1 & -- & 3.0 & -- & 5 & 0.53 & 12.5 \\
\hline CP1p & 3.1 & -- & -- & 1 & 1.5 & 3.0 & Poly- 5.0 & 5 & 0.58 & -- \\
\hline CP2p & 3.1 & -- & -- & 1 & 1.5 & 3.0 & Poly- 0.9 & 5 & 0.45 & -- \\
\hline C4p & 2.0 & -- & 1 & 1 & 1.5 & 2.8 & -- & 5 & 0.34 & -- \\
\hline C5p & 1.13 & 0.62 & 0.94 & 1 & 1.5 & 2.6 & -- & 5 & & -- \\
\hline
\end{tabular}

Table 2. 28 day flexural strength

\begin{tabular}{rcc|cc|cccccc}
\hline$\left(\mathrm{N} / \mathrm{mm}^{2}\right)$ & C1p & C1Sp & C1Ap & C2d & C3p & C3Ap & CP1p & CP2p & C4p & C5p \\
\hline Cast Beam & & 7.0 & & & 4.0 & 3.82 & 4.9 & & 6.2 & 8.1 \\
In-situ Beam & 5.9 & 6.8 & 7.9 & 6.2 & 5.9 & 4.11 & & 6.8 & & 5.7 \\
Sprayed Mould & & 3.5 & 7.8 & & & & & 6.3 & & \\
\hline
\end{tabular}

Note: Bad voids in C1S sprayed mould

Table 3. Hardened density

\begin{tabular}{rll|ll|llllll}
\hline$\left(\mathrm{kg} / \mathrm{m}^{3}\right)$ & C1p & C1Sp & C1Ap & C2d & C3p & C3Ap & CP1p & CP2p & C4p & C5p \\
\hline Cast Cube & 2167 & 2221 & & & 2231 & & 2102 & & 2307 & 2326 \\
In situ Cube & 2162 & 2247 & 2222 & 2245 & 2179 & 2147 & 2178 & 2312 & 2298 & \\
Sprayed Mould & 2084 & 2165 & 2239 & & 2223 & 2092 & 2218 & 2190 & & 2347 \\
\hline
\end{tabular}

Table 4. Sorptivity

\begin{tabular}{|c|c|c|c|c|c|c|c|c|c|c|}
\hline$\left(\mathrm{mm} / \mathrm{min}^{0.5}\right)$ & C1p & C1Sp & C1Ap & C2d & C3p & СЗАр & CP1p & CP2p & C4p & C5p \\
\hline Top slice & 0.117 & 0.096 & 0.138 & 0.202 & 0.204 & & 0.179 & 0.140 & 0.107 & \\
\hline Bottom slice & 0.060 & 0.068 & 0.122 & 0.184 & 0.133 & & 0.105 & 0.085 & 0.073 & \\
\hline
\end{tabular}

Table 5. Dry-process sprayed concrete comparison

\begin{tabular}{cccccccc}
\hline Mix & $\begin{array}{c}\text { Cube } \\
\text { Strength } \\
(\mathrm{MPa})\end{array}$ & $\begin{array}{c}\text { Density } \\
\left(\mathrm{kg} / \mathrm{m}^{2}\right)\end{array}$ & $\begin{array}{c}\text { Flexural } \\
\text { Strength } \\
\left(\mathrm{N} / \mathrm{mm}^{2}\right)\end{array}$ & $\begin{array}{c}\text { Bond } \\
\text { Strength } \\
(\mathrm{MPa})\end{array}$ & $\begin{array}{c}\text { Modulus of } \\
\text { Elasticity } \\
\left(\mathrm{kN} / \mathrm{mm}^{2}\right)\end{array}$ & $\begin{array}{c}\text { Sorptivity } \\
\left(\mathrm{mm} / \mathrm{min}^{0.5}\right)\end{array}$ & $\begin{array}{c}28 \text { Day } \\
\text { Shrinkage } \\
(\text { microstrain })\end{array}$ \\
\hline C1p in-situ & 51.0 & 2162 & 5.9 & 2.63 & & 0.060 & 789 \\
C1p cast & 58.6 & 2167 & & --- & 23.0 & & 757 \\
C2d dry & 54.2 & 2245 & 6.2 & 2.3 & 27.5 & 0.184 & 690 \\
\hline
\end{tabular}




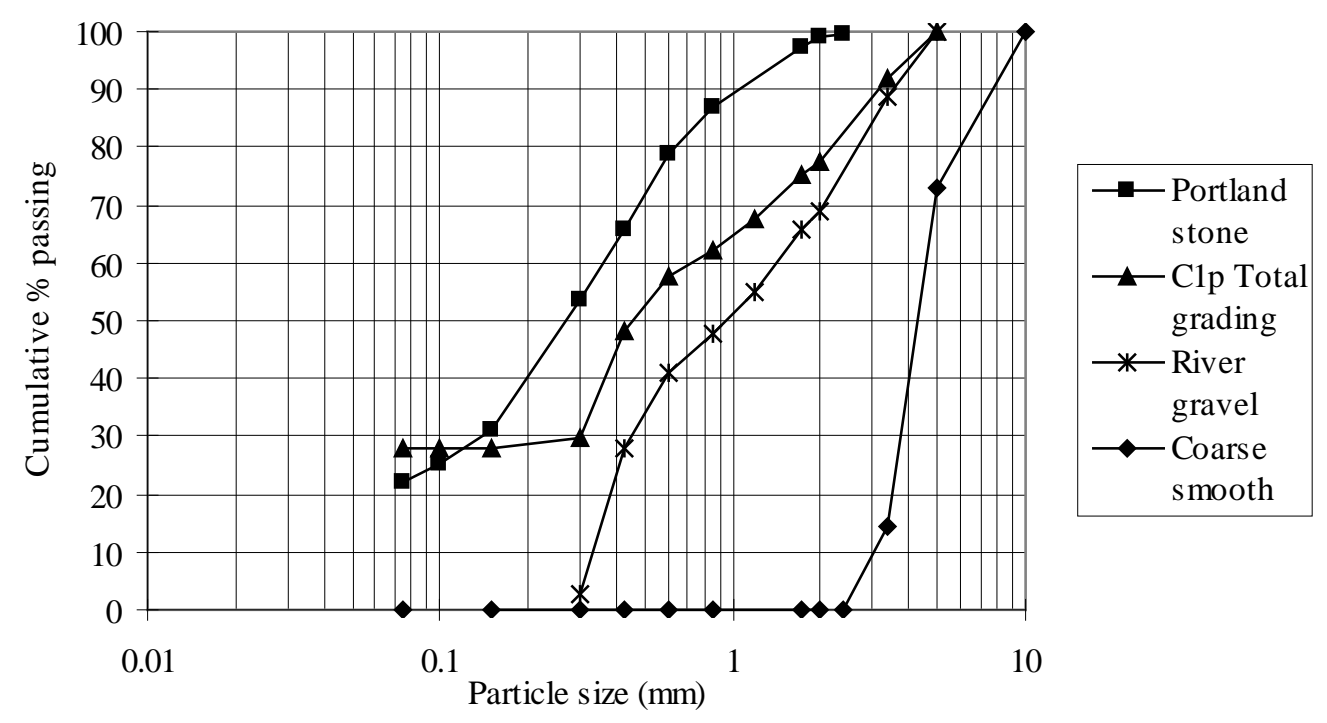

Figure 1 Grading of aggregates and mix C1p

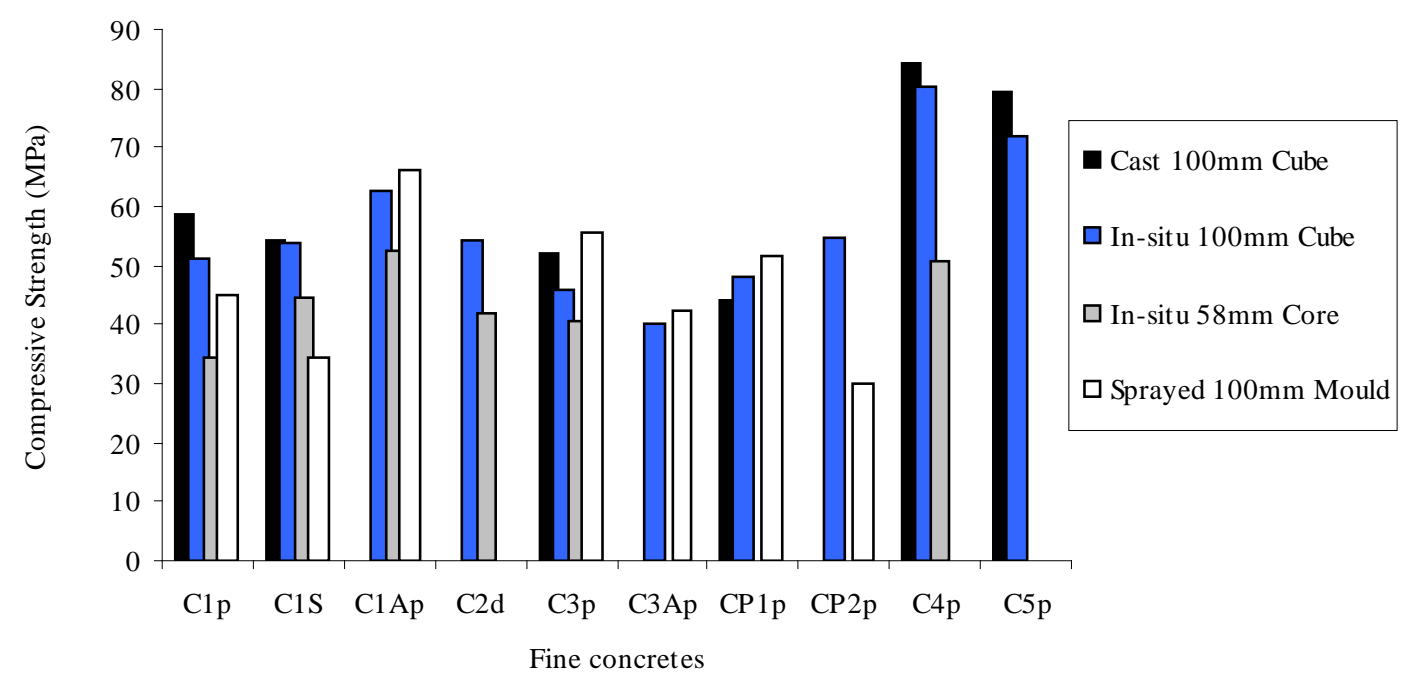

Figure 2. Compressive strengths of fine concretes

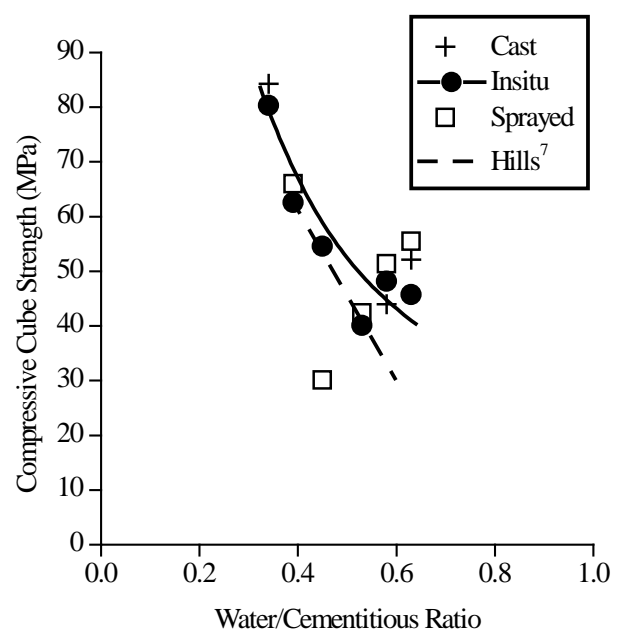

Figure3. Compressive cube strength vs Water/cementitious ratio 


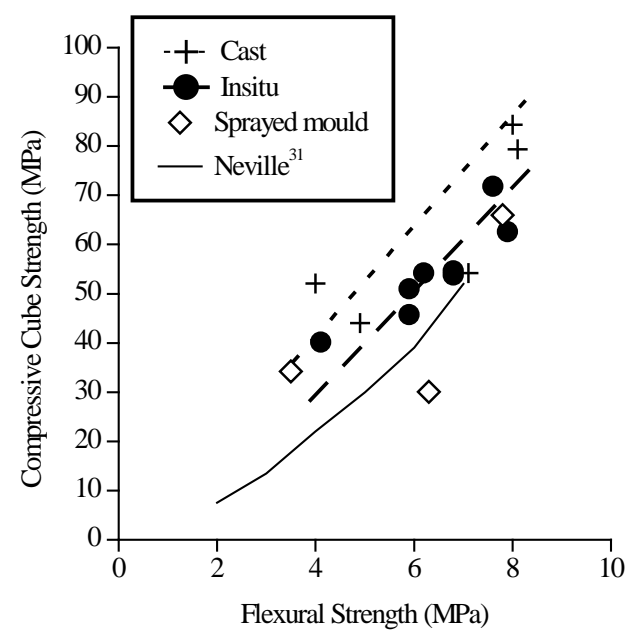

Figure 4. Flexural strength vs compressive cube strength
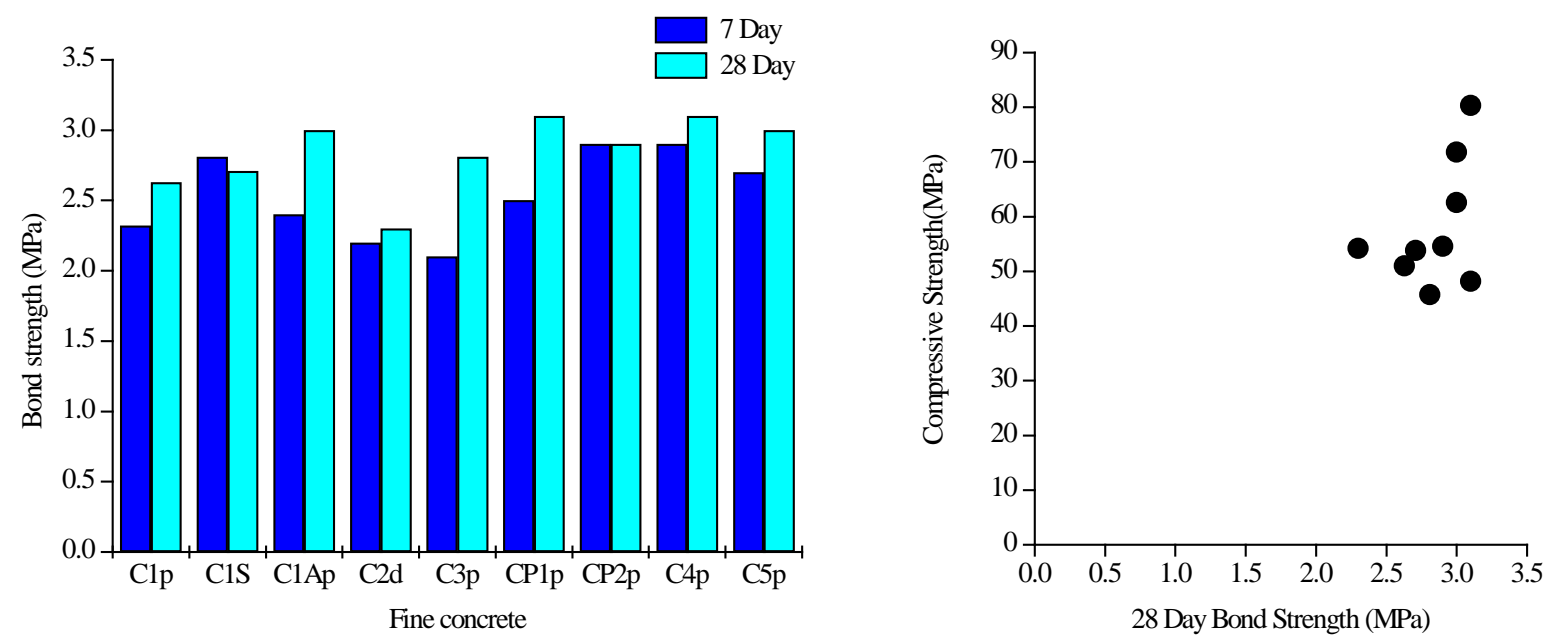

Figure 5. Bond strength (a) 7 and 28 day (b) vs In-situ compressive cube strength

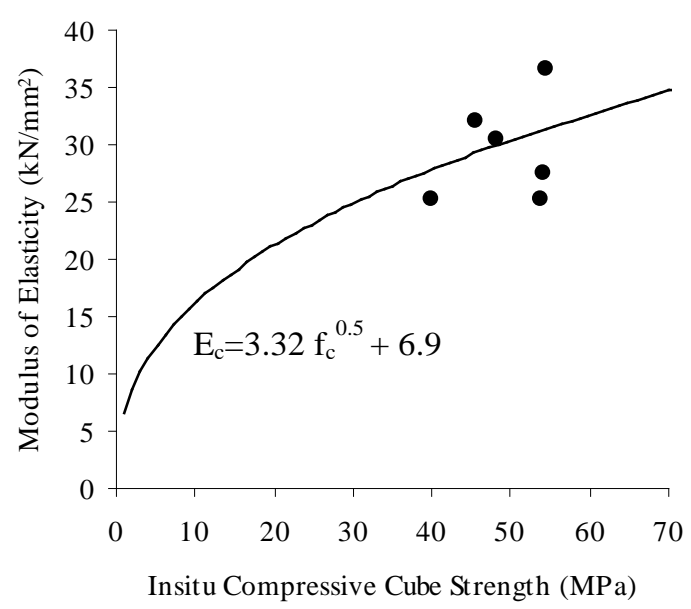

Figure 6. Modulus of elasticity vs insitu cube strength 


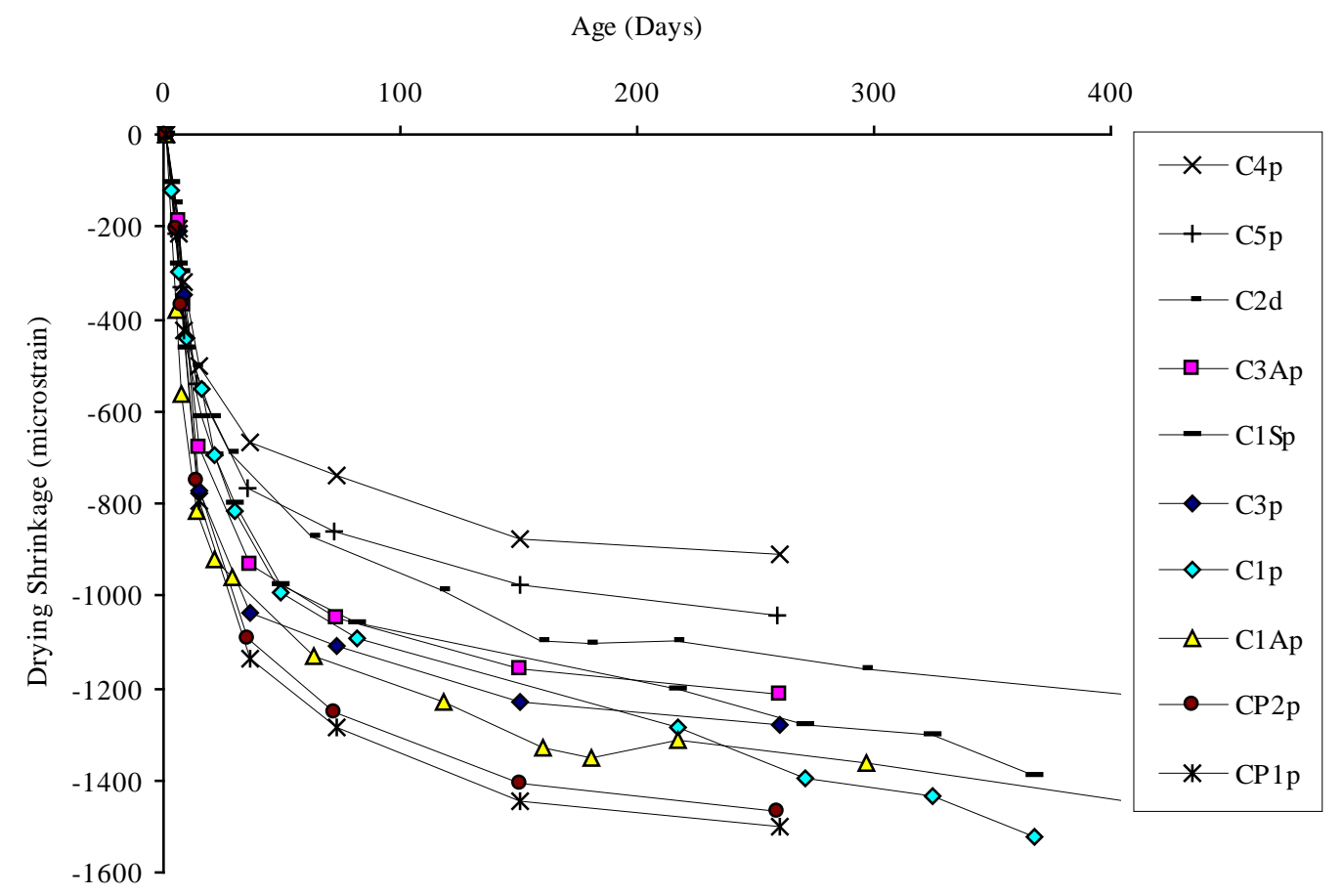

Figure 7. Drying shrinkage of prisms taken from insitu material

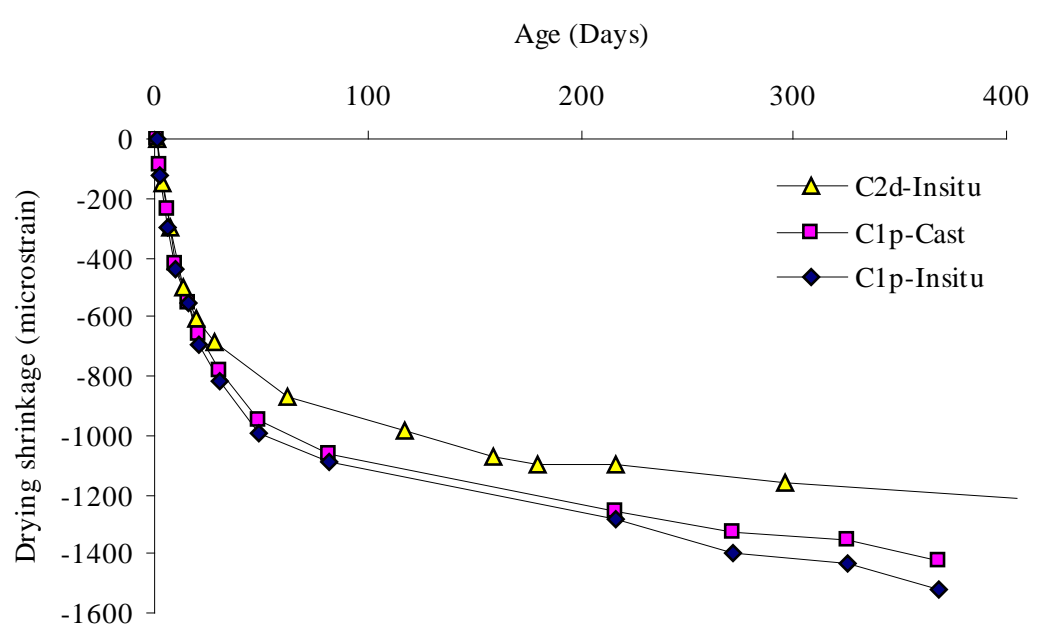

Figure 8. Drying shrinkage of C1p and C2d 
Low-volume wet-process sprayed concrete: hardened properties

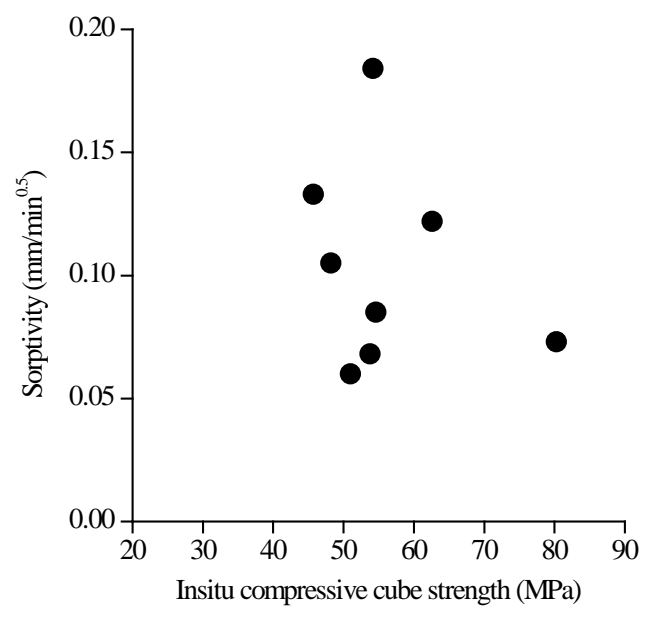

Figure 9. Sorptivity vs insitu compressive strength

Age (Days)

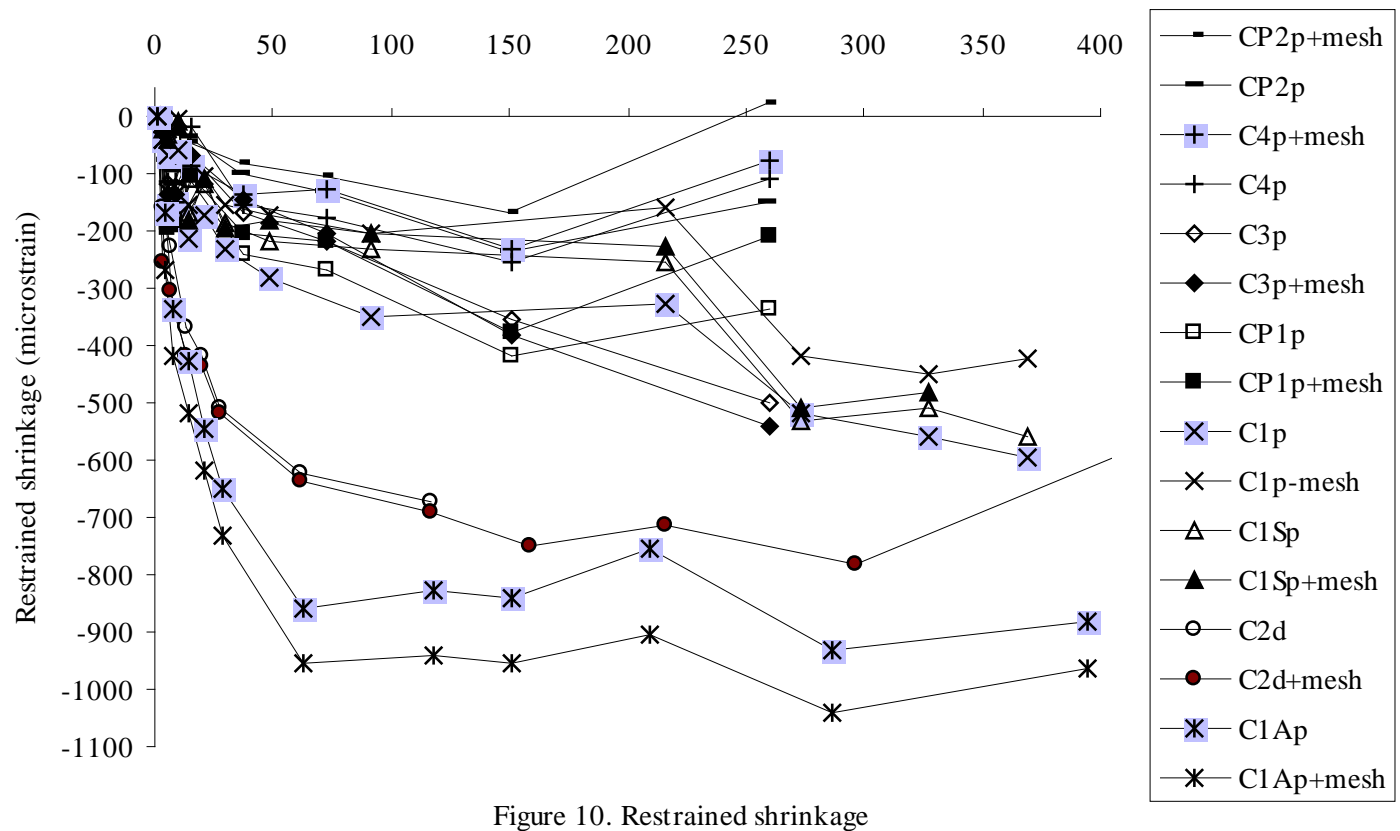

Figure 10. Restrained shrinkage

Age (days)

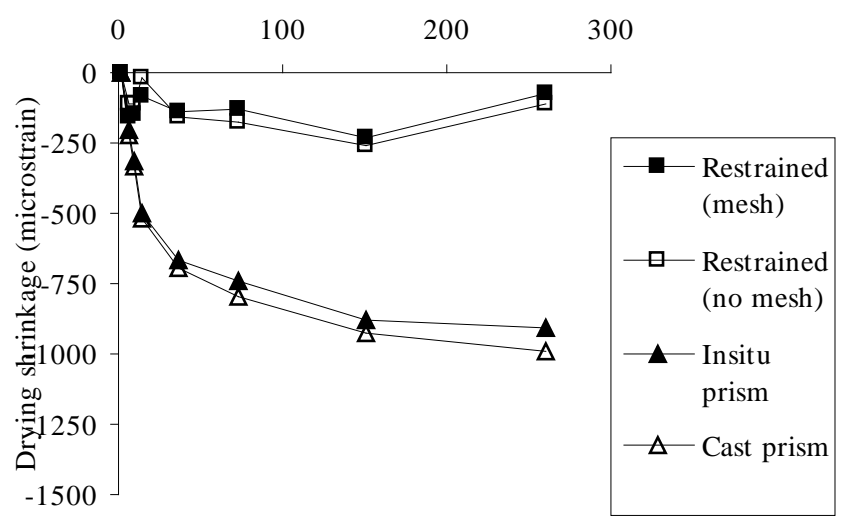

(a)
Age (days)

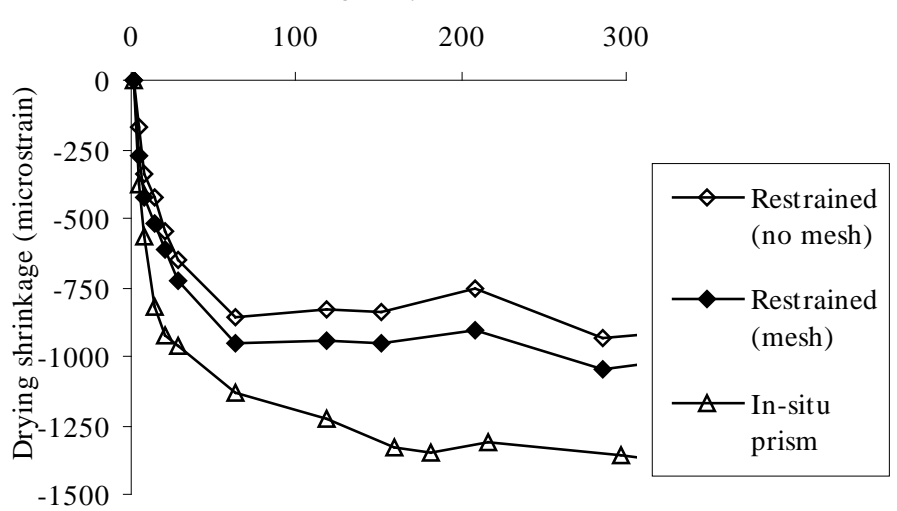

(b)

Figure 11. Restrained and drying shrinkage of (a) C4p and (b) C1Ap 